\title{
SINDICALISMO DOCENTE EM TEMPOS DE RETROCESSOS: A PARTICIPAÇÃO NO SINDICATO DOS TRABALHADORES EM EDUCAÇÃO PÚBLICA DO PARÁ, SUBSEDE CASTANHAL
}

\author{
Victor Fernando Ramos de Oliveira \\ Maria Edilene dos Santos Ribeiro \\ Odete da Cruz Mendes \\ Universidade Federal do Pará (UFPA), Belém, Pará, Brasil
}

\begin{abstract}
Resumo: Este artigo aborda o sindicalismo docente e foca sua análise no Sindicato dos Trabalhadores em Educação Pública do Pará (SINTEPP), sub sede Castanhal. Tem como objetivo central discorrer sobre o sindicalismo como espaço de organização e luta dos trabalhadores, de modo especial da educação no município de CastanhalPA. Para a discussão, foi realizado um estudo bibliográfico e documental sobre o tema em debate. $O$ texto está estruturado em três sub tópicos, no primeiro é feita uma abordagem sobre a relação entre capital e trabalho em meio às contradições, crises e reformas do sistema capitalista; no segundo apresenta-se de forma pontuada o surgimento do sindicato e suas finalidades, destacando o sindicalismo docente no Brasil; ao final abordamos o SINTEPP sub sede Castanhal, destacando algumas de suas lutas e conquistas.
\end{abstract}

Palavras-chave: Sindicalismo. Sindicalismo docente. Capital. Trabalho.

INTRODUÇÃO

Neste artigo abordamos o sindicalismo docente, com o Sindicato dos Trabalhadores em Educação do Pará (SINTEPP), sub sede Castanhal, como foco de investigação. Surge de estudos teórico e documental advindos da pesquisa sobre o Sindicalismo docente e a participação dos professores das redes de ensino castanhalense. ${ }^{1}$

O interesse pela temática vem do nosso engajamento nos movimentos sociais que lutam pela educação pública, gratuita e de qualidade e da necessidade de debater $e$ estudar o sindicato como espaço de resistência, sobretudo no contexto político educacional dos últimos anos no Brasil e com a eleição do atual presidente da República, cujo governo realiza o desmonte da educação pública.

Neste artigo temos como central a questão: "Em meio às contradições, crises e reformas do sistema capitalista, como os sindicatos, de modo especial o SINTEPP sub sede Castanhal, vem reagindo em prol da classe trabalhadora?" Temos como objetivo principal discorrer sobre o sindicalismo como espaço de organização e luta dos trabalhadores, de modo especial da educação no Município de Castanhal-PA. Como objetivos específicos, 
pretendemos: a) situar a relação entre capital e trabalho como elementos basilares do sistema capitalista; b) ressaltar a organização sindical como instrumento de enfrentamento na luta de classes; c) pontuar lutas e ações significativas do SINTEPPCastanhal.

O município de Castanhal é um dos 144 (cento e quarenta e quatro) municípios do Pará e está localizado na região nordeste desse estado, a $70 \mathrm{~km}$ da capital Belém. 0 SINTEPP-Castanhal agrega professores e demais trabalhadores da educação pública que atuam na rede municipal e estadual desse município. Atualmente tem 662 (seiscentos e sessenta e dois) filiados, dos quais 446 (quatrocentos e quarenta e seis) são professores da rede municipal.

Com um levantamento bibliográfico foram selecionados autores que estudam e pesquisam o assunto em questão, o que contribui em relevância para a fundamentação nas análises dos dados e conhecimento da história dos sindicatos e do contexto no qual vêm se desenvolvendo. $O$ estudo documental tem as Atas de assembleia do SINTEPP sub sede Castanhal como principal fonte de informação, extraindo delas dados sobre a implantação, organização, lutas e conquistas no Município de Castanhal.

Estruturalmente, organizamos este texto em três sub tópicos. No primeiro fazemos uma abordagem sobre a relação entre capital e trabalho em meio às contradições, crises e reformas do sistema capitalista. Num segundo momento, buscamos de forma pontuada mostrar o surgimento do sindicato e suas finalidades, destacando o sindicalismo docente no Brasil e, por fim, no terceiro tópico abordamos o SINTEPP sub sede Castanhal com sua relevância para a organização dos trabalhadores em educação, destacando algumas lutas e conquistas.

\section{ENTRE O CAPITAL E O TRABALHO: CONTRADIÇÕES, CRISES E REFORMAS}

Para discorrermos sobre o sentido do sindicato na sociedade do capital é necessário adentrarmos, ainda que brevemente, na trajetória histórica do sindicalismo operário, considerando que seu surgimento e desenvolvimento são decorrentes da estrutura econômica e social centrada no sistema capitalista, com suas crises e contradições.

Para Mészáros (2009), a estrutura do sistema capitalista gera fortes contradições, pois visa à acumulação do capital na classe burguesa, à exploração da classe trabalhadora e gera as crises que trazem consigo o crescimento do desemprego numa escala assustadora e a miséria humana de forma acentuada.

O sistema capitalista e suas crises, portanto, desumanizam e retiram as condições de existência dos seres humanos, como enfatiza Sampaio Junior (2009) ao afirmar que:

A crise instaura a guerra fratricida entre capital novo e capital velho. A reprodução das forças sociais que fundam a sociedade burguesa passa a depender do sucateamento das forças produtivas redundantes, da aceleração do processo de concentração e centralização dos capitais e do aumento da taxa de exploração do trabalho. Nessas circunstâncias, o desenvolvimento capitalista aparece em sua plenitude como regressão econômica e catástrofe 
OLIVEIRA, V. F. R. de; RIBEIRO, M. E. dos S.; MENDES, O. da C.

social. A relação de causalidade entre capitalismo e barbárie é levada à sua expressão máxima (SAMPAIO JUNIOR, 2009, p. 8-9).

Compreendemos que a produção material está relacionada à categoria "trabalho", pois é da exploração da força do trabalhador que o capital se desenvolve: quanto mais alta a taxa de exploração maior é o acúmulo de lucro. Ao mencionar o trabalho no contexto de produção, é importante ressaltar que é por meio do trabalho que se permite distinguir os homens dos animais, pois os primeiros produzem seus meios de vida em prol de sobrevivência. Assim, a relação entre homem e natureza só é possível pela mediação do trabalho, que é uma categoria fundamental a ser considerada ao discutirmos o sistema capitalista, suas contradições e crises.

Nesse sentido, Marx (2004) afirma que:

O trabalhador se torna tanto mais pobre quanto mais riqueza produz, quanto mais a sua produção aumenta em poder e extensão. O trabalhador se torna uma mercadoria tão mais barata quanto mais mercadorias cria. Com a valorização do mundo das coisas aumenta em proporção direta a desvalorização do mundo dos homens (MARX 2004, p. 80).

Desse modo, na sociedade do capital, o produto fruto da força de trabalho aparece como um ser estranho ao próprio trabalhador que, para possuí-lo, precisará pagar por ele e, dependendo de seu custo no mercado, não terá condições de obtê-lo. Trata-se da objetivação do trabalho: "[...] quanto mais objetos o trabalhador produz, tanto menos pode possuir e tanto mais fica sob o domínio do seu produto, do capital" (MARX, 2004, p. 81).

Na relação dual entre o capital e o trabalho, Mészaros (2002, p. 106-107) assinala que "o capital chegou à dominância no reino da produção material paralelamente ao desenvolvimento das práticas totalizadoras que dão forma ao Estado Moderno". Nessa relação, as ações do Estado burguês vêm sendo determinadas pelo objetivo de acumulação do capital, de forma a assegurar e proteger o sistema capitalista.

Na expansão do poderio econômico, afirma Bianchi (2007), o Estado forte para o capital é imprescindível para sua acomodação dentro do mercado mundial e manutenção de altas taxas de produtividade a partir da exploração dos trabalhadores, mesmo se para isso for necessário agir com repressão ao movimento dos trabalhadores.

Na contramão da lógica capitalista, Marx e Engels (1998) afirmam que o pressuposto de toda a existência humana é o de que todos os homens devem ter condições de viver e usufruir das condições materiais. Isso remete à produção dos meios que permitem satisfazer essas necessidades, a produção da própria vida material.

Diversos direitos necessários à vida, dentre os quais educação com qualidade, historicamente vêm sendo negados de várias formas à classe trabalhadora, sobretudo pela aliança do Estado neoliberal com a classe burguesa que, por meio de reformas, criam políticas que exploram cada vez mais a classe trabalhadora, inclusive retirando direitos conquistados, como é o caso das ações dos grupos neoliberais no Brasil. 
O neoliberalismo surge com o esgotamento do Estado de Bem-Estar Social e do modelo de produção fordista/taylorista, trazendo profundas mudanças no mundo do trabalho, influenciadas pelo novo modelo de produção, o toyotismo. As reformas implantadas no Brasil a partir da década de 1990 são baseadas no Consenso de Washington, ocorrido nos EUA em 1989, que teve por objetivo a expansão do projeto neoliberal nos países latino-americanos, e pela pressão de instituições internacionais como: Fundo Monetário Internacional (FMI), Banco Mundial, Banco Internacional de Reconstrução e Desenvolvimento (BIRD), Organização Mundial do Comércio (OMC) e Organização das Nações Unidas para a Educação, Ciência e Cultura (UNESCO).

Mais recentemente, no governo do presidente Michel Miguel Elias Temer Lulia (2016-2018), ${ }^{2}$ tem-se o aprofundamento de políticas neoliberais que culminaram em uma sucessão de golpes aos direitos sociais e à democracia, tidos como princípios constitucionais.

Dentre as suas medidas tem-se a Emenda Constitucional 95/2016, conhecida como a "PEC do teto dos gastos públicos", que limita por 20 anos os gastos públicos e respalda um novo regime fiscal para os Poderes da União; além do que, tem efeitos devastadores no setor educacional pois dificulta o cumprimento das metas do Plano Nacional de Educação. Nessa perspectiva, a EC 95:

[...] promoverá mais desigualdade social, mais concentração de rendas e um recrudescimento da vida daqueles que são mais vulneráveis, pois, se apresentam em todas as áreas sociais, como educação, saúde, previdência social e assistência social (AMARAL, 2016. p. 671).

Destaca-se também a Lei n. 13.467/2017, promulgada pela Presidência da República em 13 de julho de 2017, conhecida como "reforma trabalhista", defendida pelos neoliberais em nome de suposta "modernização" e crescimento econômico do país, e rejeitada pelos sindicatos e movimentos sociais devido à desproteção jurídica do trabalhador e perda de seus direitos.

Ao analisar os fundamentos e medidas da reforma trabalhista, Teixeira et al. (2017) observam que seus efeitos são prejudiciais em diferentes aspectos, uma vez que, dentre outros fatores, promoverá uma fragilização das organizações sindicais, redução de direitos e, de modo geral, a deterioração das condições de vida e de trabalho (TEIXEIRA et al., 2017, p. 111).

Observa-se que o governo Temer, sob o pretexto de busca do equilíbrio fiscal, gerou as condições para promover um amplo e profundo ataque aos direitos dos trabalhadores e ainda restringiu o direito à educação pública de qualidade, problemática que vem se estendendo no governo de Jair Messias Bolsonaro, eleito em 2018.

Diante das contradições do sistema capitalista e das reformas implementadas pelo Estado neoliberal, que retiram os direitos sociais e vêm desumanizando os sujeitos pela via da negação de suas condições materiais necessárias à existência, é que concebemos o sindicato como um espaço de organização e luta dos trabalhadores. A sua existência é entendida como um produto da luta de classe existente na sociedade e, mais precisamente, produto da divergência entre o capital e o trabalho. 
OLIVEIRA, V. F. R. de; RIBEIRO, M. E. dos S.; MENDES, O. da C.

\section{O SINDICALISMO: TRAÇOS HISTÓRICOS E CONCEITUAIS}

Foi no contexto da revolução industrial que, segundo Araújo Filho (2015), surgiu a associação sindical dos trabalhadores. O período era demarcado pelo advento da classe burguesa e da negação dos direitos elementares aos seus empregados que, motivados pela necessidade de melhores condições materiais de vida, reivindicavam melhorias trabalhistas. Para Engels (1985, p. 242), "a revolta dos operários contra a burguesia começou pouco depois do início do desenvolvimento da indústria e atravessou diversas fases", sendo que somente em 1824 os operários conquistaram o direito de livre associação.

Concebemos o sindicato como uma organização dos trabalhadores criada para "lutar contra as ordens despóticas do capital" (MARX; ENGELS, 1980, p. 13). Nessa forma de organização não se visa somente às lutas locais e imediatas, embora sejam legítimas e necessárias, mas, sobretudo, compete avançar para as lutas mais gerais e políticas, objetivando a radical emancipação da classe trabalhadora.

Corroboramos Gramsci (1976) ao enfatizar que o sindicato revolucionário tem como premissa as lutas em prol de transformação na estrutura social. Nesse sentido, não deve contentar-se com meras reformas promovidas pelo Estado. Ademais, os sindicatos se limitarão, perdendo sua essência, ao atuarem somente nas lutas imediatas acerca de condições de trabalho e salário.

Importante frisar que, para Gramsci (1976), a formação teórica contribui para que a classe trabalhadora assimile conceitos que a instigue em organizar-se para o enfrentamento político-ideológico contra a burguesia. Diante disso, concebemos que a luta sindical não é apenas relacionada ao aspecto econômico, mas também se relaciona à luta política-ideológica. Assim, entendemos que o sindicato pode limitar-se na luta pelo imediato, apresentando uma atitude centrada em reforma, ou adquirir uma atitude reacionária ao aproximar-se do Estado burguês ou, de outro modo, encaminhar suas ações para a superação e conquista deste Estado pelos trabalhadores, expressando assim uma atitude revolucionária.

Ao se identificar como uma organização revolucionária, o sindicato deve buscar distanciar-se da cooptação do poder estatal, obter sua independência em relação ao Estado e suas decisões devem ocorrer de forma coletiva e consciente pelos trabalhadores, o que requer uma base e direção democrática para evitar que as decisões fiquem sob o controle de um sujeito ou determinado grupo.

A origem dos sindicatos no Brasil ocorreu no contexto de transformações advindas do processo de industrialização da economia nacional no final do século XIX, marcado pela proibição da escravidão no Brasil em 1888, um fato social que colaborou para o processo de industrialização (CRUZ, 2008).

Conforme Rossi e Gerab (2009), os imigrantes que fugiam do desemprego em seus países foram importantes no enfrentamento aos patrões e na criação dos sindicatos no Brasil, já que eles trouxeram os ideais anarquistas, socialistas e comunistas que caracterizaram as diferentes correntes políticas no movimento dos trabalhadores. Correntes essas que "[...] apesar de suas divergências, tinham em comum a luta pela primazia do trabalho sobre o capital, ou seja, a primazia do ser humano sobre o lucro" (ROSSl; GERAB, 2009, p. 24). 
No contexto da $1^{\text {a }}$ guerra mundial, no Brasil os trabalhadores estavam com salários irrisórios e os alimentos com os preços elevados, fatores que contribuíram para promover uma grande agitação em diversos lugares do país. Dentre os movimentos ressaltamos a Greve Geral ocorrida em São Paulo, em 1917, que reuniu aproximadamente 80 mil pessoas e que teve "[...] um final vitorioso, conquistando aumento salarial de 20\%" dentre outras conquistas (ROSSI; GERAB, 2009, p. 28).

O movimento organizado dos trabalhadores, ao contrapor-se à exploração advinda do sistema capitalista, deu-se sob a repressão do Estado, defensor dos interesses da burguesia. E nesse ínterim, à medida que os sindicatos se fortaleciam, o Estado se via obrigado a buscar estratégias para manter o controle sobre os mesmos. Sob pressão da classe trabalhadora, por volta da década de 1930 o Estado instituiu uma legislação trabalhista com vistas a controlar essa pressão e escamotear a luta de classes, além de "[...] garantir um sindicalismo dócil, manso, incapaz de atrapalhar a acumulação de capital no Brasil" (GIANNOTTI, 1988, p. 09).

O governo da época, de Getúlio Vargas, no primeiro momento tenta trazer para dentro do Estado os sindicatos, iniciando assim um controle sobre essas entidades. Para tal cria o Ministério do Trabalho; promulga a Lei Sindical, em 1931 e com isso, lança orientações para o sindicalismo no país. Concebe os sindicatos como colaboradores do Estado, como se não existisse luta de classes, e impõe restrições ao movimento sindical (CRUZ, 2008, p. 23).

Observa-se que dessa forma dá-se uma estratégia de cooptação/atrelamento do sindicato ao Estado, uma vez que a existência e funcionamento dos sindicatos precisaram ser reconhecidos pelo Ministério do Trabalho, o que resulta em um intervencionismo estatal nas organizações sindicais.

O movimento de cooptação, segundo França (2013), não atingiu todos os trabalhadores, uma vez que muitos continuaram na luta para construir um sindicalismo combativo, de resistência e contra a verticalização sindical e características assistencialistas, aspectos estes que vinham sendo assumidos por muitos sindicatos.

De acordo com Cruz (2008), foi no processo de resistência, após uma greve que reuniu cerca de 700.000 pessoas em 1963, que os trabalhadores conquistaram um significativo aumento de $80 \%$ em seus salários. Todavia, no ano seguinte, com o golpe militar, os trabalhadores sofreram duros ataques e lideranças sindicais que discordaram da ordem vigente e resistiram ao regime foram presas ou mortas.

Vicentini e Lugli (2009) afirmam que é nesse período de repressão que os sindicatos docentes se fortalecem de forma autônoma na luta trabalhista, fato este considerado tardio dadas as condições sociais e políticas do país. Ressalta-se que, antes da Constituição de 1988, a sindicalização dos funcionários públicos não era permitida, mas houve a exceção do Sindicato dos Professores do Rio de Janeiro, (SINPRO-RJ) que foi criado em 1931, visto que o setor privado podia organizar-se como sindicato desde que estivesse subordinado ao governo. Nesse mesmo período, haviam professores da educação pública organizados em associações que não eram controladas pelo governo e também não tinham um compromisso classista, por serem corporativistas. 
OLIVEIRA, V. F. R. de; RIBEIRO, M. E. dos S.; MENDES, O. da C.

É no final dos anos 70 que começa a surgir um novo sindicalismo,

[...] com a marca da autonomia e da contestação à ordem estabelecida, reivindicando o fim do sistema autoritário e a volta da democracia ao país [...] contra o arrocho salarial, e por mudanças econômicas que atendessem os interesses da sociedade brasileira (MISAILIDIS, 2001, p. 66).

Oliveira (2010) afirma que no final da década de 1970 ocorrera um intenso movimento dos professores na luta pela profissionalização do magistério no sentido de romper com ideias tradicionalistas, como o exercício da profissão por vocação ou sacerdócio, e ao mesmo tempo se buscava o reconhecimento social e econômico, sendo essa luta uma manifestação de defesa desses trabalhadores frente à perda de autonomia e desqualificação do seu trabalho.

Nesse sentido, Rêses (2011) enfatiza que, com o rompimento da ideia de mestresacerdote, o professorado passou a assumir a identidade de classe trabalhadora e, portanto, a participar ativamente no sindicato. Para Misailidis (2001), a partir de 1978 inicia uma segunda etapa do sindicalismo no Brasil, quando o sindicalismo oficial, ligado ao governo, passa a ser um sindicalismo que concebe os problemas sociais e econômicos com maior profundidade e articulado ao aspecto político e de luta de classe.

Misailidis (2001) destaca ainda que, no decorrer dos anos 80, o funcionalismo público adere e se insere nesse movimento "reivindicatório e combativo", diferente do que acontecia anteriormente quando as associações tinham um caráter mais cultural e assistencialista.

Conforme Maués (2012), os docentes no Brasil se organizaram de maneira mais efetiva somente a partir de 1990, momento em que ocorre a implantação do neoliberalismo juntamente com a ideia de modernização do Estado, ${ }^{3}$ contribuindo na criação das condições para a implementação das Reformas do aparelho do Estado.

Em meio à globalização, qualidade total, Estado mínimo, terceirização e gerencialismo, o neoliberalismo resulta para os trabalhadores na intensificação do trabalho e perda de direitos. Assim, as reformas dos anos de 1990 afetaram de maneira significativa a educação brasileira, dentre outros aspectos, na formação do professor e no trabalho docente. A intensificação e a precarização apresentam-se como marcas da exploração do trabalhador docente, que cada vez mais é distanciado de seus direitos e adentra a classe proletária.

Oliveira (2010) ressalta que, a partir das reformas dos anos de 1990, os professores passam a assumir maior responsabilização pelo desempenho dos alunos e da escola, cujos resultados são balizados em avaliações externas. Além disso, os docentes precisam apresentar habilidades e competências para assumir diversificadas tarefas e funções, acarretando em excesso de responsabilidade e adoecimento, e contribuindo para o processo de desprofissionalização e da perda de identidade.

DA ASSOCIAÇÃO AO SINDICATO DOCENTE EM CASTANHAL: LUTAS E CONQUISTAS 
O movimento dos professores em Castanhal originou-se no ano de 1982, quando foi criada a "Associação dos Professores de Castanhal". Sua transformação em uma estrutura sindical ocorreu em 1989, ${ }^{4}$ após a promulgação da Constituição de 1988 (SINTEPP-CASTANHAL. Ata de transformação em delegacia sindical, 11.03.1989).

O SINTEPP-Castanhal é a representação sindical de todos os trabalhadores em educação das redes estadual e municipal..$^{5}$ Ele está estruturado em nove coordenações, cada uma contendo dois cargos, resultando numa direção de dezenove trabalhadores. Essa representatividade surgiu em 28 de outubro de 1982 com a fundação da Associação dos Professores de Castanhal (APC), destinada a "promover o desenvolvimento profissional e pessoal de seus membros" (SINTEPP SUBSEDE CASTANHAL. Estatuto da APC, 1983). A criação dessa associação ocorreu num período em que os professores da rede pública de ensino, assim como os demais servidores públicos, estavam proibidos de se organizarem em sindicato.

Atualmente, essa organização sindical é uma subunidade da estrutura do Sindicato dos Trabalhadores em Educação Pública do Pará (SINTEPP), que coordena as demais subunidades existentes em diversos municípios paraenses, sendo filiado à Confederação Nacional dos Trabalhadores em Educação (CNTE) desde 1983, ano em que também se filiou à Central Única dos Trabalhadores (CUT), mas em 2008 desfiliou-se por decisão de sua base (LUZ, 2017).

Em sua trajetória, detectamos lutas e vitórias sobre as quais faremos alguns apontamentos. Mas primeiramente destacamos que a participação sindical é de grande relevância, sobretudo neste momento de grandes retrocessos não apenas da conjuntura político-econômica-social de Castanhal, mas do Brasil e do mundo, reflexos das transformações que ocorrem no mundo do trabalho, levando à perda de direitos dos trabalhadores.

Sua atuação expressa um envolvimento político-social, bem como a participação no controle social no cenário municipal em temas que extrapolam os debates trabalhistas de sua categoria, pois em vários momentos de sua trajetória é possível identificar a participação de seus membros no Conselho do FUNDEB, no Conselho Municipal de Educação, no Conselho Municipal de Saúde, no Conselho da Alimentação Escolar e no Conselho Estadual de Representantes, além da participação em conferências municipais, abarcando um conjunto de espaços que discutem as formulações e controle das políticas públicas.

Dada a relevância dos conselhos na construção de uma democracia descentralizada e participativa, Gohn (2007, p. 7) afirma que eles são "canais de participação que articulam representantes da população e membros do poder público estatal em práticas que dizem respeito à gestão de bens públicos".

Nesse sentido, garantir o fortalecimento das organizações dos trabalhadores, como o SINTEPP-Castanhal, é fundamental na disputa no cenário político-econômicosocial marcado pelas políticas neoliberais que investem no "[...] desmonte dos sindicatos, e movimento sociais" de contestação à ordem burguesa (FRIGOTO; MOLINA, 2010, p. 43). E a participação da base sindical é elemento-chave para esse fortalecimento. 
Na relação estabelecida com o Estado, entre governo municipal e o sindicato como representante dos trabalhadores, o choque de interesses é quase inevitável na medida em que o Estado, em sua premissa neoliberal, não tem interesse na valorização do trabalho ou mesmo no diálogo da construção e efetivação das políticas sociais. Assim, na conjuntura de Castanhal, o enfrentamento do sindicato ocorre, principalmente, com o governo municipal de Castanhal, e os pontos de conflitos são decorrentes, sobretudo em relação ao salário. Porém, conforme esclarecido em uma assembleia geral extraordinária, a diretoria geral do sindicato postula a seguinte afirmativa: "[...] a nossa reivindicação não é só por salários, é também por melhorias de uma maneira geral na educação municipal" (SINTEPP SUBSEDE CASTANHAL, Ata da Assembleia Geral, 10.06.1989).

O que corrobora Gouveia e Ferraz (2013) ao afirmarem que, na história da organização dos docentes, as pautas de reivindicações estão para além do salário, alcançando lutas por políticas educacionais que incidem na qualidade da educação. A própria luta por formação profissional para os professores de Castanhal é antiga, conforme podemos identificar nos registros da APC, que datam do ano de 1984.

Entre outras reivindicações está a não demissão de trabalhadores sem justa causa, visto que essa é uma prática recorrente por questões político-eleitorais e também pelo discurso de corte de gastos (SINTEPP SUBSEDE CASTANHAL, Ata da Assembleia Geral, 10.06.1989; Ata Reunião da Diretoria, 14.09.1991; Ata da Assembleia Geral, 11.02.1993), o que põe o trabalhador numa profunda instabilidade de vida e de subsistência, enfim, numa situação de submissão àqueles que assumem o governo municipal. Por esse motivo a luta por concurso público tem sido também uma bandeira permanente levantada por esse sindicato.

As paralisações e greves são formas de enfrentamento que o sindicato tem utilizado para colocar em evidência os conflitos, diante dos quais os governos se negam a dialogar ou buscam silenciar os trabalhadores em educação. Engels $(1985$, p. 253) afirma que as greves "não decidem nada definitivamente, mas são a prova mais segura que a batalha decisiva entre o proletariado e a burguesia se aproxima. São escolas de guerra dos operários, onde eles se preparam para o grande combate".

Entendemos que as greves não só demonstram a força dos trabalhadores perante o Estado como também podem ser momentos que a classe utiliza para organizarse para o enfrentamento político. Nessa direção, enfatizamos que quando a classe ainda não chegou nem mesmo à consciência de si, é mais estratégico utilizar o momento de greve como momento pedagógico do que como enfrentamento em si, visto que isso não exclui ou mesmo diminui o enfrentamento com o governo, e sim contribui para o fortalecimento do poder de ação dos trabalhadores.

A decisão de uma greve geralmente é tomada pela categoria, pois como observamos no histórico de enfrentamento, no caso de Castanhal, o movimento grevista enfrentou as reações do patrão, o governo, como nos mostra o registro da ata da Assembleia Geral Extraordinária do dia 10.06.1989, informando que o secretário de educação municipal objetivou desmobilizar os trabalhadores durante uma greve:

Foi nos informado que o Secretário de educação está fazendo reunião nas escolas, pressionando os trabalhadores e tentando desmobilizá-los, chegando ao ponto de agredir fisicamente um membro da diretoria (SINTEPP SUBSEDE CASTANHAL, Ata da Assembleia Geral Extraordinária, 10.06.1989). 
Observamos que outra reação significativa do governo municipal à luta sindical dos trabalhadores em educação ocorreu em 1992, quando o mesmo criou outro sindicato, o SEPUC, ${ }^{6}$ e de forma autoritária o instituiu como representante dos professores e à revelia dos trabalhadores realizou descontos para este novo sindicato:

Foi colocado também a respeito do SEPUC, sindicato imposto classe, sem sequer uma consulta prévia aos trabalhadores com direitos a descontos sem a autorização dos funcionários e direcionado por secretários e assessores do sr. Prefeito, assim jamais colocar-se-á ao lado do trabalhador. Os funcionários repudiaram esta atitude comunicando o reconhecimento do SINTEPP como seu verdadeiro representante (SINTEPP SUBSEDE CASTANHAL, Ata de Assembleia Geral, 20.03.1992).

A partir dos elementos históricos apresentados pelos documentos analisados, observamos que a história do SINTEPP-Castanhal o afirma como uma organização legítima da categoria docente no município. Nessa direção, os documentos revelam os momentos significativos dos enfrentamentos com o governo municipal, seja na reivindicação de melhorias à educação, principalmente a valorização salarial do professor, seja contra atitudes autoritárias do Poder Público no sentido de desmonte do sindicato.

A articulação do SINTEPP-Castanhal com a comunidade escolar e outras organizações de trabalhadores foi constatada nos documentos analisados, sobretudo através da participação nos conselhos municipais. Essa inserção em espaços de debates contribui para superação do corporativismo que pode estar presente em maior ou menor grau na estrutura do sindicalismo brasileiro.

Sobre a participação da categoria no sindicato, com base nas atas de eleição percebemos que a filiação oscilou em vários momentos da história da organização, embora o quantitativo de filiação não reflita na prática em participação real, pois visualizamos que há momentos na história do sindicato em que a baixa participação efetiva da categoria contribuiu para enfraquecimento das lutas e resultou em cortes de salários daqueles poucos que ousavam enfrentar o governo.

E no atual estágio de decomposição do capitalismo, quando ele tenta assegurar a todo custo o seu processo de acumulação, o antagonismo entre as classes se acirra devido à deterioração das condições de existência da classe trabalhadora. Nesse contexto, Abramides (2017, p. 371) acredita que "há uma possibilidade histórica de revolução social" em meio às atuais condições objetivas provocadas pela força destrutiva do capitalismo que incitam uma transformação, porém é necessário também que sejam construídas condições subjetivas para a classe trabalhadora desempenhar seu papel revolucionário. Contudo, esse será um trabalho da própria classe trabalhadora, e aí está a importância da mediação feita pelas organizações da classe, como os sindicatos e partidos, na perspectiva revolucionária.

É importante frisar que os sindicatos, especialmente no caso em estudo, não devem ter suas lutas pautadas somente por lutas imediatas, economicistas, democráticas, que são necessárias, mas não o bastante para a superação da dicotomia entre o capital e o trabalho. Assim, é imprescindível visar à raiz da lógica da acumulação, da desigualdade, 
e avançar para as lutas nas esferas política, ideológica, social e cultural, pois isto é inevitável para a construção de uma consciência revolucionária e de uma nova forma de sociabilidade.

\section{CONSIDERAÇÕES FINAIS}

O estudo nos mostra que a organização dos trabalhadores no Brasil e no mundo ocorreu em um processo conectado às precárias condições de trabalho e vida aos quais estes estavam submetidos no processo de industrialização. Assim, identifica-se o fator salário como principal ponto conflitivo inicial que desencadeou a luta organizada dos trabalhadores.

Dessa forma, a condição da legalidade do sindicato foi inevitável, visto a ampla dimensão que a organização estava tomando naquele período. $E$, ao longo de sua trajetória, os sindicatos têm adquirido várias faces, formas de intervir na realidade: há aqueles que apresentam suas lutas dentro das rédeas do sistema de acumulação capitalista, e há outros que lutam visando à emancipação dos trabalhadores e à superação desse sistema de acumulação que beneficia poucos, regado à exploração de muitos. Assim, o sindicalismo revolucionário é identificado por suas ações que superam a luta imediata, econômica, e sobretudo tem a compreensão da necessidade da luta política para romper com a lógica vigente.

O trabalhador da educação, além de viver com sobrecarga de atividade, sofrimento, cansaço, o que afeta sua saúde causando-lhe adoecimentos, não tem as condições materiais necessárias para desempenhar o seu trabalho e ter qualidade de vida.

Nesse sentido, Marx (2008) e Engels (2008) afirmam que a luta por melhores salários e jornada de trabalho são legítimas, porém elas não podem ser tomadas como fim, pois a lei do salário é parte da lógica do capital. Daí a necessidade de ampliar o horizonte das lutas sindicais para além das lutas imediatas, econômicas.

Desse modo, certamente a luta pela valorização da educação e dos professores no município de Castanhal implica em uma luta política, e nessa arena estão presentes os antagonismos de classes, e os dados e suas análises nos mostram que quando se trata de servidores públicos, o governo e o Estado neoliberal usam estratégias para cooptar ou desmontar a organização trabalhista.

Nesse confronto, é fundamental que os sindicatos não fiquem somente com a postura defensiva, mas que possam articular ações ofensivas de lutas reais que culminem na emancipação da classe trabalhadora. Para encaminhar essas lutas, um dos grandes desafios dos sindicatos encontra-se em organizar a categoria, pois sem essa organização dificilmente terá conquistas, ainda que no campo das lutas imediatas.

Nessa perspectiva, tem-se a necessidade de quebrar com a velha ordem que põe a acumulação de capital acima da humanidade, e a saída para a atual crise do capital, que tem governos ultraconservadores assumindo o Estado, exige mudanças estruturais que ultrapassam aquelas mudanças parciais que tentam humanizar o capitalismo, como se isso fosse possível. 
Precisamos da transformação das estruturas dessa sociedade desigual e, para tal, almejamos que, de alguma forma, este estudo possa apontar e contribuir para a construção de uma nova sociedade que esteja assentada na igualdade, cooperação, solidariedade, companheirismo, fraternidade, amor, justiça, coletividade, respeito às diferenças.

Artigo recebido em: 09/11/2019

Aprovado para publicação em: 17/05/2020

\section{TEACHERS' UNIONISM IN REGRASSION TIMES: THE PARTICIPATION IN WORKERS' UNION IN PUBLIC EDUCATION OF THE STATE OF PARÁ, SUB HEADQUARTER CASTANHAL}

ABSTRACT: This article discusses teachers' unionism and focuses its analysis of the Workers' Union in Public Education of the State Of Pará (SINTEPP) sub headquarter Castanhal. It's main objective discuss about unionism as a space for workers' organization and struggle, especially the education in the city of Castanhal-PA. For the discussion, a bibliographic and documentary study was conducted on the topic under discussion. The text is structured in three subtopics, in the first one an approach is made about the relation capital and labor amidst the contradictions, crises and reforms of the capitalist system; In the second, the emergence of the union and its purposes is punctuated, highlighting the teaching unionism in Brazil; At the end we discuss about the SINTEPP, sub headquarter Castanhal, highlighting some of its struggles and achievements.

KEYWORDS: Unionism. Teaching unionism. Capital. Work.

UNIÓN DE MAESTROS EN TIEMPOS DE RETROMENTO: PARTICIPACIÓN EN EL UNIÓN DE TRABAJADORES DE EDUCACIÓN DE PARÁ, SUBSEDE CASTANHAL

RESUMEN: Este artículo aborda el sindicalismo de los docentes y centra su análisis en la sede central del Sindicato de Trabajadores de la Educación de Pará (SINTEPP), subsede Castanhal. Su objetivo principal es discutir el sindicalismo como un espacio para la organización y la lucha de los trabajadores, especialmente la educación en el municipio de Castanhal-PA. Para la discusión, se realizó un estudio bibliográfico y documental sobre el tema en discusión. El texto está estructurado en tres subtemas: en el primero se aborda la relación capital y trabajo en medio de las contradicciones, crisis y reformas del sistema capitalista; En el segundo, se destaca el surgimiento del sindicato y sus propósitos, destacando el sindicalismo docente en Brasil; Al final, discutimos sobre la sede central de SINTEPP Castanhal, destacando algunas de sus luchas y logros.

PALABRAS CLAVE: Sindicalismo. Sindicalismo docente. Capital. Trabajo. 
OLIVEIRA, V. F. R. de ; RIBEIRO, M. E. dos S.; MENDES, O. da C.

NOTAS:

1) A pesquisa em tela fora concluída em 2019 no curso de Mestrado do Programa de Pós-graduação em Educação, da Universidade Federal do Pará. O sindicato investigado fora o SINTEPP-Subsede Castanhal.

2) Esse presidente assumiu interinamente o cargo de presidente da república após o afastamento de Dilma Rousseff que, em consequência de um golpe de Estado, teve o mandato cassado no dia 31 de agosto de 2016.

3) A ideia central do neoliberalismo é a que o Estado é responsável pela crise - que na realidade é do capital - e por isso deve atuar de maneira a não interferir nas leis do mercado, promovendo privatizações, abertura comercial e desregulamentação financeira e do trabalho. (BOITO JUNIOR, 1998).

4) Uma das diferenças entre a associação e o sindicato está no fato de que "a associação atua em nome, apenas, de seus associados, enquanto o sindicato em prol de toda a categoria profissional ou econômica, independentemente de filiação". (CESÁRIO, 2017).

5) Incluem-se na categoria de associados todos os professores/as, especialistas e funcionários/as das escolas públicas da rede estadual e municipal que estejam em atividade ou aposentado. (SINTEPP. Estatuto do SINTEPP, 2017).

6) Ao ser mencionado na Ata da Assembleia Geral de 20 mar. 1992, a sigla do sindicato SEPUC não é posta por extenso. Mesmo em registros posteriores, não há menção do significado da sigla. Importante esclarecer que nos documentos coletados não foi possível identificar como este sindicato [SEPUC] foi encerrado, mas também não encontramos indícios de que ainda exista, portanto, fica subentendido que suas atividades foram encerradas.

\section{REFEREENCIAS}

ABRAMIDES, M. B. C. Lutas sociais e desafios da classe trabalhadora: reafirmar o projeto profissional do serviço social brasileiro. Serviço Social e Sociedade, São Paulo, n. 129, p. 366-385, maio/ago. 2017.

AMARAL, N. C. PEC 241/55: a "morte" do PNE (2014-2024) e o poder de diminuição dos recursos educacionais. Revista Brasileira de Política e Administração da Educação, Porto Alegre, v. 32, n. 3, p. 653 -673, dez. 2016.

ARAÚJO FILHO, J. G. O sentido do sindicalismo na tradição marxista: a educação da classe trabalhadora na fronteira das lutas econômicas, politicas e ideológicas. 2015. 108 f. Dissertação (Mestrado em Educação) - Faculdade de Educação, Universidade Federal do Ceará, Fortaleza, 2015.

BIANCHI, A. O marxismo de Leon Trotsky: notas para uma reconstrução teórica. Idéias, Campinas, v. 14, p. 57-99, 2007.

BOITO JUNIOR, Armando. Política neoliberal e sindicalismo no Brasil. 1998. 290 f. Tese (Livre-docência) - Instituto de Filosofia e Ciências Humanas, Universidade Estadual de Campinas, Campinas, 1998.

CESÁRIO, Eliane Monteiro. Sindicato x associação: entenda as diferenças. Sinditamaraty.org, Brasília, 6 jun. 2017. Disponível em: 
https://www.sinditamaraty.org.br/comunicacao/noticias/7201-5-perguntas-sobremovimento-sindical. Acesso em: 22 jul. 2018.

CRUZ, H. L. Condições de construção histórica do sindicalismo docente na educação básica. 2008. 301 f. Tese (Doutorado em Sociologia) - Instituto de Ciências Sociais, Universidade de Brasília, 2008.

ENGELS, F. A situação da classe trabalhadora na Inglaterra. Tradução: Rosa Camargo Artigas e Reginaldo Forti. São Paulo: Global, 1985

ENGELS, Friedrich. O sistema de trabalho assalariado. In: AGUENA, Paulo (org.). 0 Marxismo e os Sindicatos. São Paulo: Sundermann, 2008.

FRANÇA, T. Novo sindicalismo no Brasil: histórico de uma desconstrução. São Paulo: Cortez, 2013.

FRIGOTTO, G.; MOLINA, H. Estado, educação e sindicalismo: no contexto da regressão social. Revista Retratos da Escola, Brasília, v. 4, n. 6, p. 37-51, jan./jun. 2010.

GIANNOTTI, V. O que é estrutura sindical. São Paulo: Brasiliense, 1988.

GOHN, M. da G. Conselhos Gestores e participação sociopolítica. São Paulo: Cortez, 2007.

FERRAZ, M. A. S.; GOUVEIA, A. B. Sindicalismo Docente e Política Educacional: tensões e composições de interesses corporativos e qualidade da educação. Educar em Revista, Curitiba, v. 48, p. 111-129, 2013.

GRAMSCI, A. Sobre Democracia Operaria e outros textos. Biblioteca Ulmeiro n.4. Lisboa/Portugal: Ulmeiro. 1976.

LUZ, S. L. O. Sindicalismo e educação no estado do Pará: as repercussões da luta sindical sobre o trabalho docente. 2017. 315 f. Tese (Doutorado em Educação) - Instituto de Ciências da Educação, Universidade Federal do Pará, Belém, 2017.

MARX, K.; ENGELS, F. Sindicalismo. São Paulo: Ched, 1980.

MARX, K; ENGELS, F. A ideologia alemã. São Paulo: Martins Fontes, 1998.

MÉSZÁROS, I. Para além do capital. Tradução: Paulo Cezar Castanheira e Sérgio Lessa. São Paulo: Boitempo, 2002.

MARX, K. Manuscritos Econômico-Filosóficos. São Paulo: Boitempo, 2004. 
OLIVEIRA, V. F. R. de ; RIBEIRO, M. E. dos S.; MENDES, O. da C.

MARX, K. As greves e as coligações de operários. In: AGUENA, Paulo (org.). O Marxismo e os Sindicatos. São Paulo: Sundermann, 2008.

MÉSZÁROS, I. A crise estrutural do capital. São Paulo: Boitempo, 2009.

MAUÉS, O. C. Organização dos docentes e ação sindical. In: MAUÉS, O. C. (org.). 0

Trabalho Docente na Educação Básica: o Pará em questão. $1^{\text {a }}$. ed. Belo Horizonte: Fino Traço, 2012.

MISAILIDIS, M. L. Os desafios do sindicalismo brasileiro diante das atuais tendências. São Paulo: Ltr Editora, 2001.

OLIVEIRA, D. Os trabalhadores da educação e a construção política da profissão docente no Brasil. Educar em Revista, Curitiba, n. especial 1, p. 17-35, 2010.

RÊSES, E. da S. O Sentido da Prática Sindical entre os Atores Sociais do Sindicalismo Docente da Educação Básica da Cidade Maravilhosa. Revista Inter-Legere (UFRN), Natal, no 9, p. 118-142, 2011.

ROSSI, W.; GERAB, W. J. Para entender os sindicatos no Brasil: uma visão classista. São Paulo: Expressão Popular, 2009.

SAMPAIO JUNIOR, P. de A. Apresentação. In: SAMPAIO Jr, Plínio de Arruda (org.). Capitalismo em Crise: A natureza e dinâmica da crise econômica mundial. São Paulo: Editora Instituto José Luís e Rosa Sundermann, 2009. p. 10-15.

SINTEPP SUBSEDE CASTANHAL. Estatuto da APC, 1983.

SINTEPP SUBSEDE CASTANHAL. Ata da Assembleia Geral. Castanhal, 10 jun.1989.

SINTEPP SUBSEDE CASTANHAL. Ata Reunião da Diretoria. Castanhal, 14 set. 1991.

SINTEPP SUBSEDE CASTANHAL. Ata da Assembleia Geral. Castanhal, 11 fev. 1993.

SINTEPP. Estatuto do SINTEPP, Belém, 2017.

TEIXEIRA, M. O. et al. Contribuição crítica à reforma trabalhista. Campinas, SP: UNICAMP/IE/CESIT, 2017.

VICENTINI, P. P.; LUGLI, R. G. História da profissão docente no Brasil: representações em disputa. São Paulo: Cortez, 2009. 
Victor Fernando Ramos de Oliveira: Graduado em Licenciatura em Educação Física pela Universidade Federal do Pará (2014). Mestre em Educação pela linha de Políticas Públicas Educacionais do Programa de Pós-Graduação em Educação da Universidade Federal do Pará (2019).

Orcid: https://orcid.org/0000-0002-9592-7380

E-mail: vitorbelem@hotmail.com

Maria Edilene dos SAntos Ribeiro: Professora doutora, atua como docente e pesquisadora na Faculdade de Pedagogia do Campus Universitário de Castanhal e no Programa de Posgraduacao em Educação da Universidade Federal do Pará.

Orcid: https://orcid.org/0000-0002-0989-0391

E-mail: mariaedileneribeiro@yahoo.com.br

Odete da Cruz Mendes: Professora doutora, atua como Professora Associada I da Universidade Federal do Pará, Campus Universitário do Tocantins/Cametá, vinculada ä Faculdade de Educação (FAED/Cametá) e credenciada ao Programa de Pós-Graduação e Cultura - PPGEDUC/UFPA.

Orcid: https://orcid.org/0000-0002-1475-3922

E-mail: ocm@ufpa.br

Este periódico utiliza a licença Creative Commons Attribution 3.0, para periódicos de acesso aberto (Open Archives Iniciative - OAI) 